\title{
EVALUATION OF DRUG/LIGAND BINDING CONSTANTS FOR HUMAN SERUM ALBUMIN USING DIFFERENTIAL SCANNING CALORIMETRY
}

\author{
Affiliations: \\ ${ }^{1}$ Department of Chemistry, Portland State University, Portland, Oregon \\ ${ }^{2}$ Department of Physics, Portland State University, Portland, Oregon \\ * Corresponding Author abenight@pdx.edu
}

Authors: Matthew W. Eskew ${ }^{1}$ and Albert S. Benight ${ }^{1,2^{*}}$

\begin{abstract}
This paper reports utilization of differential scanning calorimetry measurements to evaluate binding constants for Human Serum Albumin of 28 different drug ligands. Protein/ligand mixtures were prepared at various ligand concentrations and subjected to thermal denaturation analysis by calorimetry. From the measurements, the melting temperature, $T_{m}$, and freeenergy $\Delta G_{c a l}\left(37^{\circ} \mathrm{C}\right)$ for melting ligand-bound Albumin were evaluated as a function of ligand concentration. Concentration dependent behaviors of $\Delta G_{c a l}\left(37^{\circ} \mathrm{C}\right)$ and $T_{m}$ derived from protein/ligand mixtures were used to construct dose-response curves. Model fits of doseresponse curves yielded quantitative evaluation of the ligand binding constant, $K_{D}$, and semiquantitative estimates of the binding stoichiometry, $n$. Many of the ligands had known binding affinity for Albumin with binding constants reported in the literature. Evaluated Albumin binding parameters for the ligands impressively agreed with reported literature values determined using other standard experimental methods. These results demonstrated utility of our calorimetrybased process for applications in pre-clinical drug screening.
\end{abstract}

\section{INTRODUCTION}

Methods for analyzing binding of ligands to proteins are crucial for a number of applications. One of central importance is analysis of drug/ligand binding to Human Serum Albumin (HSA). Assessment of plasma protein binding (PPB) of new drug candidates is an integral component of pre-clinical drug discovery and protein engineering. For the purpose of this study, the terms ligand and drug are used interchangeably to mean binding entities. In essence, all drugs are ligands but not all ligands are necessarily drugs.

At $60 \%$ by mass of all plasma proteins HSA is the most prominent. ${ }^{1-4}$ Intrinsic to its biological activities, HSA is directly involved in transport and distribution of therapeutic drugs in the blood. This activity can directly impact desired pharmacological effects of a therapeutic drug. A multiplicity of reactive sites on HSA have been identified, and several with known binding affinities for a variety of different drugs. ${ }^{5-7}$ The pharmacokinetics (ADME properties) of administered therapeutic agents can be greatly impacted by the enormous binding capacity of 
HSA, and binding of other plasma proteins. Both experimental and computer studies have extensively analyzed site-specific drug binding in HSA. ${ }^{8-10}$ The prominence of HSA among plasma proteins and the central role HSA plays in bioavailability of drugs, makes it an important screening target. Screening of new drug candidates for HSA binding and analysis is central to their preclinical evaluation and development.

Supply of new drug candidates exceeds current screening capacity. This is primarily due to the use of ineffective high-throughput screening methods. The result is bottlenecks in the development pipeline and ultimately lower availability of potentially effective drug candidates. Improved methods for rapid, quantitative screening of new drug candidates for their PPB activity, could aid considerably in loosening disruptive bottlenecks and expediting the drug discovery process. ${ }^{11}$ At least $90 \%$ of all new drug candidates fail. Improved screening methodologies capable of rapidly evaluating protein binding properties are needed to provide deeper insight into relationships between molecular and chemical characteristics of targets and drug candidates. This information provides the means to establish correlations between specific physical and chemical attributes of drugs and their targets. Such correlations can then be employed in the functional design and optimization of biochemical properties of new drug candidates. These improvements could aid to reduce the failure rate of new drugs and could have significant impact on the early pre-clinical drug discovery process.

Generally, when a drug/ligand recognizes and binds to a protein, depending on the nature of binding (electrostatic, polar, hydrophobic, etc.) it can either stabilize or destabilize the protein with respect to thermal or chemical denaturation. Thus, relative to the unbound protein, when bound the melting temperature (or concentration of denaturant) required to unfold the protein is either increased or decreased. Interactions between circulating drug/ligands in plasma with HSA can affect protein thermodynamic stabilities, thereby influencing the shape of the melting curve or thermogram of drug/ligand-bound HSA. ${ }^{12-14}$ In this sense, thermograms measured by differential scanning calorimetry (DSC) are highly sensitive to drug/ligand binding interactions.

This enhanced sensitivity of ligand-bound HSA compared to free HSA is due to a direct linkage between ligand binding and thermodynamic stability of the protein. ${ }^{15}$ The nature of this linkage is two-fold. Ligand binding to a protein as a function of increased ligand concentration results in increases in melting transition temperatures, $T_{M}$, of ligand-bound protein complexes. Not unexpected this observation is simply a well-known manifestation of Le Chatelier's principle as applied to protein-ligand binding. ${ }^{16,17}$ That is if a ligand binds preferentially to the native rather than denatured state the thermal stability will be increased. Provided the measured calorimetric enthalpy of the heat-induced denaturation transition of the ligand-bound protein remains constant, as ligand concentration is increased, the observed shift in stability with ligand binding forms the foundation of any standard temperature shift assay. ${ }^{16}$

However, if the measured melting enthalpy of the ligand-bound protein does change with increased ligand concentrations then (as has been observed) ${ }^{15}$ this is an indication that the equilibrium thermodynamic stability of the native protein structure has also changed due to ligand binding. Therefore, observed changes in thermal stability also reflect directly on 
thermodynamic consequences of structural (perhaps subtle or not so subtle) perturbations of the protein conformation and stability associated with ligand binding.

Depending on the type and strength of binding interactions, temperature shifts on thermograms of proteins in the presence of ligands can be dramatic (easily tens of degrees). These "T-shifts" along with increases in the melting enthalpies of drug/protein complexes that are associated with binding of ligand can be far more significant than detectable variances in either mass or charge that accompany binding. Consequently, compared to other standard methods, DSC derived thermograms can be more sensitive to binding interactions.

DSC is a well-known physical technique commonly used for detailed quantitative analysis of protein stability. Thus, it is surprising that relatively little attention has been given to application of DSC for analysis of drug/protein interactions. This because previous attempts to utilize DSC for drug binding analysis have met with limited success. ${ }^{18-20}$ Recently we reported on a fast, reliable and accurate procedure using DSC measurements that enables evaluation of thermodynamic parameters for ligand bound protein. There are a number of favorable features of this analytical approach. These include: (1) ease of sample preparation and experimental execution, (2) small volume of sample required ( $500 \mu \mathrm{L})$, (3) no prior knowledge of binding activity required, (4) short processing time (less than 90 minutes), (5) Fully amenable to automated, high-throughput format for parallel screening applications.

Collective features of the process provide a promising alternative approach with which to interrogate drug/protein interactions, and argue that DSC could prove to be a potentially superior screening alternative.

\section{MATERIALS AND METHODS}

Protein Samples: Human Serum Albumin (HSA) ( $\geq 99 \%$ pure, Lot number: SLBT8667) was purchased from Sigma Aldrich (St. Louis, MO) and received as lyophilized power.

Buffers and Reagents: Standard buffer for all experiments contained $150 \mathrm{mM} \mathrm{NaCl}, 10 \mathrm{mM}$ potassium phosphate, $15 \mathrm{mM}$ sodium citrate, $\mathrm{pH}=7.4$.

Solutions of HSA: All protein samples were prepared in standard buffer as stock solutions at a concentration of $1.0 \mathrm{mM}$ and stored at $4^{\circ} \mathrm{C}$ for at least 24 hours before use. For DSC melting experiments protein samples were $27-28 \mu \mathrm{M}(\sim 2 \mathrm{mg} / \mathrm{mL})$ determined spectrophotometrically. ${ }^{5}$, 21-24

Drug Samples: Drug/ligands for this study were procured from commercial suppliers. Naproxen (NAP), bromocresol green (BCG), ibuprofen (IB), captopril (CAP), thimerosal (TMS), fluorescein (FSC), caffeine (CAF) Digitoxin (DTX), bilirubin mixed isomers (BIL), tetracaine (TET), $\beta$-Estradiol (BST), and chloroquine (CQ) were purchased from Sigma Aldrich (St. Louis, MO). Decanoic acid (DCA) was purchased from Acros Organics (Geel, Belgium). Metformin (MET) was from MP Biomedical (Irvine, CA); metoprolol (MEP) from Alfa Aesar (Haverhill, MA); buproprion 
hydrochloride (BPR) from Tokyo Chemical Industry (Tokyo, Japan); Multihance (MH) and Prohance (PRO) from Bracco (Milan, Italy). Gadavist (GAD) and Magnevist (MAG) were purchased from Bayer (Leverkusen, Germany); Dotarem (DOT) from Guerbet (Villepinte, France); Ablavar (AB) from Lantheus Medical Imaging (Billerica, MA); and $\Delta 9$-tetrahydrocanabinol (THC) from Cerilliant (Round Rock, TX). The novel compound DM115725-27 was provided by Professor David Peyton (Portland State University). BP-DOTA(side), BP-DOTA(corner), NBAM-DO3A, and BPAMDO3A were prepared and provided by Professor Mark Woods (Portland State University).

\section{Sample Preparation}

Preparation of Drug Samples: Drug solids were dissolved in nanopure water to create stock solutions. Gadolinium contrast agents were provided from the manufacturer in aqueous solution. THC was a $1 \mathrm{mg} / \mathrm{mL}$ analytical standard prepared in methanol. Aqueous insoluble drugs were prepared as stock solutions in appropriate solvents; digitoxin in chloroform; ibuprofen, $\beta$ estradiol, and decanoic acid in ethanol.

Protein/Drug Solutions: Solutions of HSA samples for drug binding experiments contained the drug present at different concentrations. Protein concentration was constant in all mixtures at 27-28 $\mu \mathrm{M}$. Protein/Drug solutions were prepared by adding the desired amount of drug to the protein solution and incubating at $4^{\circ} \mathrm{C}$ for 24 hours prior to testing.

Drug/Ligand Solubilization Procedure: Stock solutions of drug compounds were pipetted into separate $2 \mathrm{~mL}$ microcentrifuge tubes to yield the correct molar amounts of drug for a $1 \mathrm{~mL}$ working (drug/protein) solution. For drugs with reported binding constants, a minimum of eight distinct drug/protein samples were prepared spanning the binding concentration regime. For drugs of unknown binding strength, a logarithmic titration of drug concentrations was utilized with further refinements depending on results.

Microcentrifuge tubes containing different amounts of drug samples dissolved in organic solvent were placed in a vacuum concentrator (Savant SpeedVac SVC100). Using standard vacuum concentrator procedures to evaporate off organic solvent containing the sample, resulted in known specific amounts of solid drug in each tube. To each tube, HSA was added at $28 \mu \mathrm{M}$ with standard buffer to produce a one $\mathrm{mL}$ working solution for measurements.

Calorimetry Measurements: DSC melting experiments were performed as recently described ${ }^{15}$, 28, 29 and summarized below (details reviewed in Supplemental Material). Data collection, reduction and analysis procedures were identical to those recently reported ${ }^{15,28,29}{ }^{\text {. DSC melting }}$ experiments measure the excess heat capacity, $\Delta C_{P}$, of the sample as a function of increasing temperature. Plots of $\Delta C_{P}$ versus temperature are commonly termed DSC thermograms. These were measured for HSA molecules in mixtures with the various ligands. At least two thermograms were measured for every sample examined.

Thermodynamic parameters determined from thermograms measured as a function of ligand concentration provided a means for evaluation of the dissociation binding constant, $K_{D} \cdot{ }^{15}$ The actual process was comprised of four steps. 
(1) Thermograms of drug/HSA complexes were measured over a variety of drug/HSA concentration ratios. These provided measurements of the melting transition temperature, $T_{m}$ and the transition enthalpy, $\Delta H_{\text {cal }}$ from which $\Delta G_{\text {cal }}\left(37^{\circ} \mathrm{C}\right)$ was determined for ligand/HSA mixtures as a function of ligand concentration.

(2) Drug concentrations served as the doses, while $\Delta G_{c a l}\left(37^{\circ} \mathrm{C}\right)$ or $T_{m}$ were the responses measured for HSA in mixtures with each drug at increasing doses. From these data DoseResponse (D-R) curves were generated in the form of $\Delta G_{\text {cal }}\left(37^{\circ} \mathrm{C}\right)$ or $T_{m}$ versus the log of the ratio of ligand to protein concentrations on a Molar scale.

(3) D-R curves from (2) were fit with versions of the modified Hill equation by varying the binding constant and stoichiometry as adjustable parameters. ${ }^{15,}$ 30-32

(4) Fits of D-R curves from (3) provided quantitative evaluation of the ligand binding constant, $K_{D}$.

(5) Comparison of D-R curves constructed using $\Delta G_{c a l}\left(37^{\circ} \mathrm{C}\right)$ and $T_{m}$ from (4) provided semiquantitative estimates of the binding stoichiometry, $n$, for each ligand binding to HSA.

\section{RESULTS AND DISCUSSION}

Drug/Ligand Samples: Chemical compounds chosen for DSC analysis of HSA binding were selected to be representative of a broad variety of drugs; all with known clinical utility. A few compounds with no reported binding activity, or poor aqueous solubility were also examined. In total, HSA binding reactions of 28 different compounds were analyzed.

Binding of 28 drugs to HSA: Typical binding data for HSA in the presence of drugs were comprised of DSC thermograms measured for a constant amount of HSA in the presence of increasing amounts of drug. The complete sets of thermograms collected for HSA in the presence of increasing concentrations and D-R curves derived from them for the 28 drugs are given in Supplementary Material.

For drugs that exhibited detectable binding to HSA there were clearly measurable variations of the HSA-bound thermograms with increasing drug concentrations. From these data quantitative values of $T_{m}$ and thermodynamic parameters $\Delta H_{c a l}, \Delta S_{c a l} \approx \frac{\Delta H_{c a l}}{T_{m}}$, and $\Delta G_{c a l}\left(37^{\circ} \mathrm{C}\right)=\Delta H_{c a l}-$ $T\left(37^{\circ} \mathrm{C}\right) \Delta S_{\text {cal }}$ were determined at each drug concentration. The values of $\Delta H_{c a l}, T_{m}$ and $\Delta G_{\text {cal }}\left(37^{\circ} \mathrm{C}\right)$ evaluated for thermal denaturation of HSA bound by the 28 drugs are summarized in Table 1 (a more detailed description can be found in Table S1 of Supplementary Material). These results are discussed subsequently. 


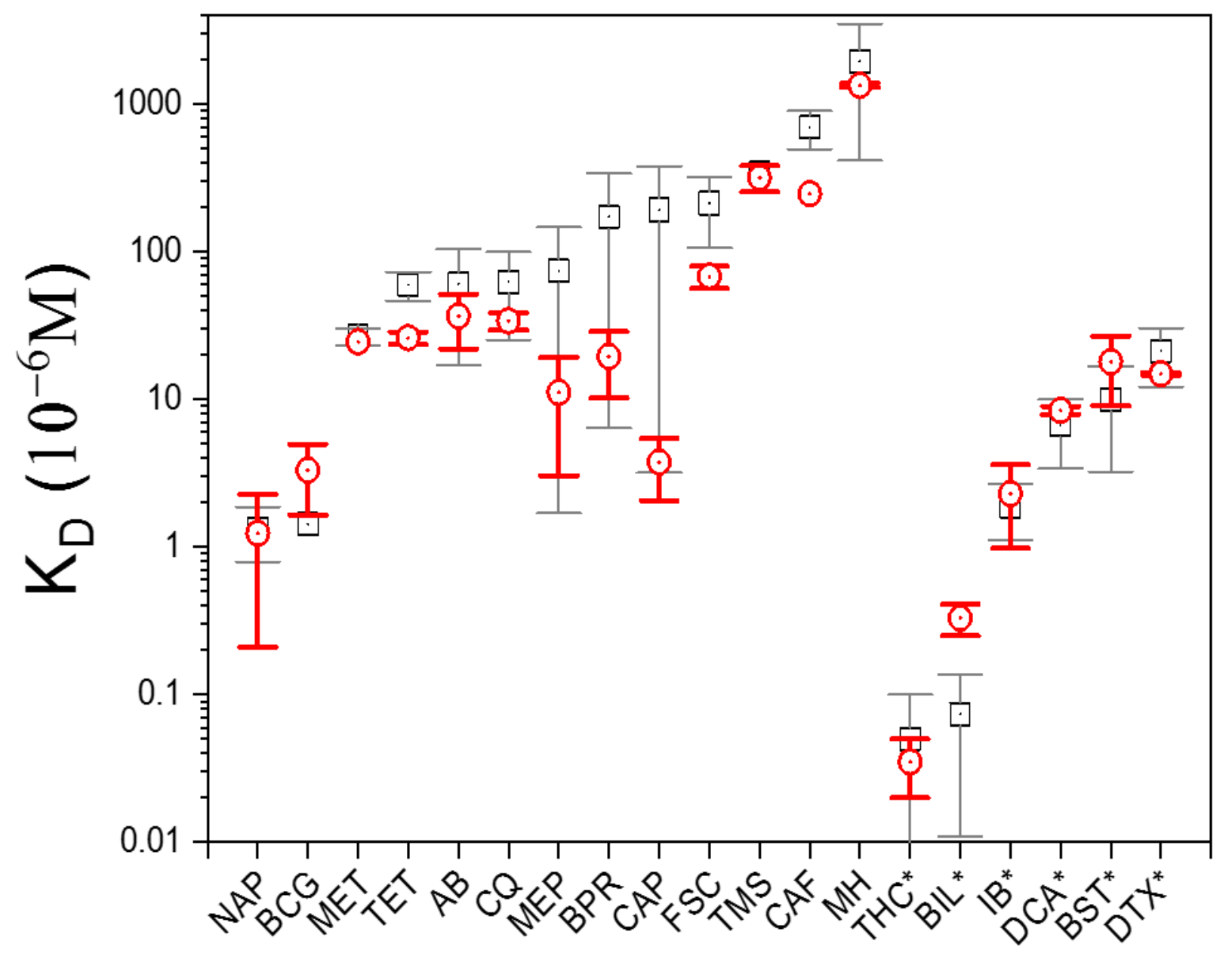

Figure 1: Measured (O) binding constants compared with literature ( $\square)$. Literature values are given in Table 1. *Insoluble or sparingly aqueous soluble compounds.

Out of the 28 drugs examined, 19 of the drugs had binding data reported in the literature. For five of the drugs, no binding data was available. Four of the drugs did not display any binding activity. Evaluated binding constants for the 19 drugs are plotted along with their reported literature values in Fig 1. Evaluated binding constants and stoichiometries for the 28 drugs with HSA are displayed in Table 1 along with their average literature values. Additional information (literature values and experimental techniques for their evaluation) can be found in Supplementary Material. As shown in Fig 1, $K_{D}$ values ranged over five orders of magnitude from $10 \mathrm{nM}$ to $1 \mathrm{mM}$ and agreed with reported values within the error.

To prospect for HSA binding activity for the four drugs with no reported binding activity, thermograms of the drug/HSA mixtures were measured at a drug concentration of $100 \mathrm{mM}$. This relatively high drug concentration would be expected to evoke some sort of a response in the form of shifted HSA thermograms induced by drug binding. The measured thermograms of these drug mixtures of HSA with $100 \mathrm{mM}$ drug concentration were identical to that of HSA alone, providing no evidence for HSA binding (Supplemental Material). 
bioRxiv preprint doi: https://doi.org/10.1101/2021.01.22.427858; this version posted January 25, 2021. The copyright holder for this preprint (which was not certified by peer review) is the author/funder, who has granted bioRxiv a license to display the preprint in perpetuity. It is made available under aCC-BY-NC-ND 4.0 International license.

\begin{tabular}{|c|c|c|c|c|}
\hline Drug & $\begin{array}{l}\text { Avg. Measured } \\
\mathrm{K}_{\mathrm{D}}\left(10^{-6} \mathrm{M}\right)\end{array}$ & $\begin{array}{l}\text { Measured } \\
\text { Stoichiometry }\end{array}$ & $\begin{array}{l}\text { Avg. Literature } \\
\mathrm{K}_{\mathrm{D}}\left(10^{-6} \mathrm{M}\right)\end{array}$ & $\begin{array}{l}\text { Literature } \\
\text { Stoichiometry }\end{array}$ \\
\hline Bromocresol Green (BCG) & $3.31 \pm 1.7$ & 3.0 & $1.43^{33}$ & $3^{33}$ \\
\hline Naproxen (NAP) & $1.24 \pm 1.0$ & 10.8 & $1.33 \pm 0.5^{34-37}$ & $1-10^{9,34-37}$ \\
\hline Chloroquine (CQ) & $33.97 \pm 4.6$ & 1.3 & $62.40 \pm 37.1^{38-40}$ & $1^{38,40}$ \\
\hline Multihance (MH) & $1335 \pm 45$ & 1.1 & $1948 \pm 1532^{41,42}$ & $1^{41,42}$ \\
\hline Ablavar (AB) & $36.61 \pm 14.7$ & 2.3 & $60.40 \pm 43.4^{41-44}$ & $\begin{array}{l}1 \text { but "potentially } \\
\text { more" } 41-44\end{array}$ \\
\hline Dotarem (DOT) & $N / A$ & -- & No Binding ${ }^{42}$ & -- \\
\hline Prohance (PRO) & $N / A$ & -- & No Binding ${ }^{42}$ & -- \\
\hline Magnevist (MAG) & $N / A$ & -- & No Binding ${ }^{42}$ & -- \\
\hline Gadovist (GAD) & N/A & -- & No Binding ${ }^{42}$ & -- \\
\hline Tetracaine (TET) & $26.13 \pm 2.5$ & 0.8 & $59.80 \pm 13.2^{45,46}$ & $1^{45,46}$ \\
\hline Captopril (CAP) & $3.75 \pm 1.7$ & 2.7 & $\begin{array}{l}191.59 \pm 188.4^{47}, \\
48\end{array}$ & $1.7^{47,48}$ \\
\hline Caffeine (CAF) & 247 & -- & $\begin{array}{l}696.2 \pm 201.2^{49-} \\
52\end{array}$ & $1^{49,50,52}$ \\
\hline Thimerosal (TMS) & $\begin{array}{l}\text { 1) } 3.13 \pm 0.43 \\
\text { 2) } 317.50 \pm 63.5\end{array}$ & $\begin{array}{l}\text { 1) } 0.8 \\
\text { 2) } 0.7\end{array}$ & $339^{53}$ & $1^{53}$ \\
\hline Fluorescein (FSC) & $3.31 \pm 1.7$ & 1.4 & $\begin{array}{l}212.03 \pm 106.2^{54}, \\
55\end{array}$ & $1^{54}-4^{55}$ \\
\hline Metformin (MET) & $\begin{array}{l}\text { 1) } 2.01 \pm 0.43 \\
\text { 2) } 24.5\end{array}$ & $\begin{array}{l}\text { 1) } 0.6 \\
\text { 2) -- }\end{array}$ & $26.73 \pm 3.6^{56,57}$ & $1^{56,57}$ \\
\hline Metoprolol (MEP) & $11.14 \pm 8.1$ & 0.2 & $74.07 \pm 72.4^{58,59}$ & 1-2 high affinity ${ }^{58,59}$ \\
\hline Buproprion (BPR) & $\begin{array}{l}\text { 1) } 0.25 \pm 0.04 \\
\text { 2) } 19.51 \pm 9.3\end{array}$ & $\begin{array}{l}\text { 1) } 1.3 \\
\text { 2) } 2.8\end{array}$ & $\begin{array}{l}172.19 \pm 165.8^{60} \\
61\end{array}$ & $1^{60}$ \\
\hline DM1157 & $0.91 \pm 0.01$ & 1.0 & $\mathrm{~N} / \mathrm{A}$ & -- \\
\hline BP-DOTA (side) & $8.55 \pm 0.7$ & 1.2 & $N / A$ & -- \\
\hline BP-DOTA (corner) & $11.41 \pm 1.0$ & 0.9 & N/A & -- \\
\hline NBAM-DO3A & $70.20 \pm 1.8$ & 1.0 & N/A & -- \\
\hline BPAM-DO3A & $16.58 \pm 5.0$ & 1.9 & $\mathrm{~N} / \mathrm{A}$ & -- \\
\hline Digitoxin (DTX)* & $14.86 \pm 0.3$ & 1.0 & $21.27 \pm 9.1^{62-64}$ & $1^{62}$ \\
\hline Ibuprofen (IB)* & $2.30 \pm 1.3$ & 3.7 & $1.89 \pm 0.8^{64-66}$ & 3 high affinity ${ }^{65}$ \\
\hline Decanoic Acid (DCA)* & $8.42 \pm 0.4$ & 0.9 & $6.70 \pm 3.3^{67-69}$ & $1^{67-69}$ \\
\hline $\begin{array}{l}\Delta 9 \text {-tetrahydrocannabinol } \\
(\mathrm{THC})^{*}\end{array}$ & $0.04 \pm 0.02$ & 2.0 & $0.05 \pm 0.1^{70}$ & $\begin{array}{l}1 \text { high affinity }{ }^{70} \\
1 \text { low } \text { affinity }^{70}\end{array}$ \\
\hline$\beta$-Estradiol (BST)* & $17.94 \pm 8.9$ & 3.2 & $9.98 \pm 6.7^{71-74}$ & "assumed n=1" 71,74 \\
\hline Bilirubin (BIL)* & $0.33 \pm 0.1$ & 1.6 & $0.07 \pm 0.1^{75-77}$ & $1^{77}$ \\
\hline
\end{tabular}


Drug/Ligand Binding Constants: For 23 of the drugs, D-R curves constructed with either $\Delta G_{c a l}\left(37^{\circ} \mathrm{C}\right)$ or $T_{m}$ displayed typical binding behavior where increasing dose concentrations led to a sigmoidal increase in response. These curves were fit well with a single $D-R$ curve and provided evaluations of binding constants in agreement with the literature. Five of the binding curves were atypical and displayed a bi-dose response or destabilization with increased drug concentration. These specific examples are described below.

Two of the drugs (thimerosal and bupropion) displayed bi-D-R curves for both $\Delta G_{\text {cal }}\left(37^{\circ} \mathrm{C}\right)$ and $T_{m}$. Analysis of the bi-D-R curves yielded two $K_{D}$ values suggestive of two distinct binding reactions. As shown in Table 1 , two binding constants were evaluated for thimerosal, $\mathrm{K}_{\mathrm{D} 1}=3.13$ $\mu \mathrm{M}$ and $\mathrm{K}_{\mathrm{D} 2}=312 \mu \mathrm{M}$ (see Table 1). The latter is consistent with the reported literature value, $\mathrm{K}_{\mathrm{D}}$ $=339 \mu \mathrm{M}^{53}$ The former requires additional considerations. One of those is that thimerosal contains an organomercury moiety; with HSA binding likely corresponding to $\mathrm{K}_{\mathrm{D} 1}$. Interestingly, binding of small organomercury compounds to the free sulf-hydryl at cys34 on HSA has been reported to be 0.1-1 $\mu \mathrm{M}$ (with $\mathrm{n}=4$ required for accurate fits). This range of values is very close to our evaluated $\mathrm{K}_{\mathrm{D} 1}=3.13 \mu \mathrm{M} .{ }^{78,79}$ Thimerosal rapidly decomposes in the presence of HSA to yield organo- $\mathrm{Hg}(\mathrm{II})$ fragments that can also bind HSA. ${ }^{78}$ Detection of two binding reactions for thimerosal is consistent with HSA binding of both whole thimerosal and an un-mercurated thimerosal fragment at its specific site on HSA. ${ }^{78}$

An analogous situation likely exists for bupropion for which the t-butylamino group is reportedly cleaved yielding two products in solution, i.e. a chlorophenyl product and t-butylamino. ${ }^{80}$ The observed bi-D-R curve likely corresponds to separate binding of the two degradation products to HSA, in a manner similar to thimerosal. The result is the observation of two separate binding constants, $K_{D 1}=0.25 \mu \mathrm{M}$ and $K_{D 2}=19.5 \mu \mathrm{M}$ (see Table 1). The average of these is $9.8 \mu \mathrm{M}$ in excellent agreement with the reported HSA binding constant of $6.37 \mu \mathrm{M} .^{60}$

For metformin, only the $T_{m}$ D-R curve was bi-phasic. This observation is possibly due to HSA binding of both metformin and a decomposition moiety. Metformin is a biguanide compound. Generally, in aqueous solutions biguanide compounds decompose to urea and other amines. ${ }^{57,81}$ These amine compounds can bind to HSA, while urea is a known protein denaturant. The bi-D-R curve for $T_{m}$ displayed a destabilizing trend for HSA as a function of drug concentration, possibly due to urea, while $\Delta G_{c a l}\left(37^{\circ} \mathrm{C}\right)$ displayed a single $\mathrm{D}-\mathrm{R}$ curve with $\mathrm{K}_{\mathrm{D}}=2.44 \mu \mathrm{M}$. The destabilizing bi-D-R curve for $T_{m}$ yielded two separate binding constants, $\mathrm{K}_{\mathrm{D} 1}=1.58 \mu \mathrm{M}$ and $\mathrm{K}_{\mathrm{D} 2}=24.52 \mu \mathrm{M}$ (see Table 1). The latter is in excellent agreement with the reported average value for metformin, $\mathrm{K}_{\mathrm{D}}=26.73 \mu \mathrm{M} .{ }^{56,57}$ Presumably the former corresponds to binding of amine degradation products. Although consistent with our results this interpretation is by no means conclusive.

Finally, captopril and metoprolol displayed a single D-R curve for $\Delta G_{c a l}\left(37^{\circ} \mathrm{C}\right)$ and a destabilizing D-R curve for $T_{m}$. Averages of evaluated binding constants for captopril and metoprolol were $K_{D}$ $=3.75 \mu \mathrm{M}$ and $11.14 \mu \mathrm{M}$, respectively (see Table 1 ). These binding constants were consistent with the reported literature values. ${ }^{47,48,58,59}$ As discussed above for metformin the presence of urea as a degradation product obviously can destabilize the protein. Origins of the destabilizing 
D-R curves for captopril and metoprolol are less obvious. For captopril it has been reported that, compared to unbound protein, the observed binding to HSA encourages formation of aggregates at lower temperatures. ${ }^{82}$ This could lead to destabilization of the native HSA structure with increasing captopril concentrations. For metoprolol, although not conclusive, circular dichroism measurements, at increasing concentrations of metoprolol, led to spectroscopic changes interpreted to indicate a decrease in $\alpha$-helical structure for bound HSA which likely could destabilize the native structure. ${ }^{58}$

For the majority of compounds, quantitative drug binding analysis was performed using simple D-R analysis. For the exceptions described above, quantitatively accurate $K_{D}$ values were obtained along with additional qualitative insight generated from HSA binding thermograms. These results were encouraging and demonstrated that our DSC approach was able to detect destabilizing behavior due to drug binding, and provide accurate drug binding constants from a single set of experiments. Further, as described below semi-quantitative estimates of the binding stoichiometry were also obtained.

Binding Stoichiometry: In some cases, differences between the D-R curves constructed using either $\Delta G_{c a l}\left(37^{\circ} \mathrm{C}\right)$ or $T_{m}$ were observed. As described below semi-quantitative estimates on the ligand binding stoichiometry could be estimated by comparison of the different binding constants evaluated from fitting the $\Delta G_{c a l}\left(37^{\circ} \mathrm{C}\right)$ and $T_{m} \mathrm{D}-\mathrm{R}$ curves. For single site binding, stoichiometry $\mathrm{n}=1$, binding constants evaluated using either $\Delta G_{c a l}\left(37^{\circ} \mathrm{C}\right)$ or $T_{m}$ were in quantitative agreement. However, for ligands with $n>1$, i.e. 2-10, ratios of the binding constants determined from $\Delta G_{c a l}\left(37^{\circ} \mathrm{C}\right)$ or $T_{m}$ doses differed, semi-quantitatively, by a factor of $\mathrm{n}$. The rationale for this observation follows.

$\Delta G_{\text {cal }}\left(37^{\circ} \mathrm{C}\right)$ was obtained from the measured $\Delta H_{\text {cal }}$ and $T_{m} . \Delta H_{\text {cal }}$ is comprised of enthalpy changes of the drug and protein target that accompany binding, and effects of binding on the thermodynamic stability of the protein. This includes intermolecular interactions of different types between drug and target. Also included in $\Delta G_{c a l}\left(37^{\circ} \mathrm{C}\right)$ are changes in entropy due to conformational changes in the drug and target upon binding. Therefore, $\Delta G_{c a l}\left(37^{\circ} \mathrm{C}\right)$ was imminently more sensitive than $T_{m}$ to individual binding events as well as overall effects of binding on HSA structure. For binding sites able to accommodate more than a single ligand, i.e. with binding stoichiometry $n>1$, effects of binding each ligand in the site are directly reflected in the evaluated $\Delta H_{c a l}$ and consequently $\Delta G_{c a l}\left(37^{\circ} \mathrm{C}\right) .{ }^{15}$

For ligand binding where $n=1, T_{m}$ shifts with increased concentrations of ligands that preferentially bind the intact native protein structure, are a natural occurrence due to Le Chatelier's principle. ${ }^{16,17}$ This leads to an increase in $T_{m}$ of the ligand-bound native structure and agrees with our results for ligands with $n=1$ stoichiometry.

Conversely, observed behavior for ligands with $n>1$ is not simply explained by Le Chatelier's principle. Accordingly, at high ligand concentrations (above stoichiometric amounts) the release of ligand by denaturation of the protein effects the melting equilibrium. However, at low ligand concentrations (below stoichiometric amounts) prior to occupation of all possible binding sites (in an equilibrium sense), re-distribution of the ligand among available binding subsites within 
the binding pocket can occur. For example Bromocresol Green has been reported to occupy all three subsites (la, Ib, Ic) within Sudlow Site I. ${ }^{33}$

Consequently, for $n>1$, ligand binding at the lowest sub-stoichiometric ligand concentrations effectively decreases the actual observed site-specific binding constant for subsequent ligand binding events. In this scenario two competing reactions are operative. The first being primary binding of ligand(s) in the binding pocket. The second being redistribution of the ligand(s) within the pocket. Once ligand concentration is high enough to decrease likelihood of redistribution, and the primary binding reaction dominates the process, then titratable increases in $T_{m}$ are observed.

An alternative possibility is that the ligand can bind at more than one site with relatively high affinity; but binding at some of these binding sites may not be sufficient to affect the melting transition of ligand-bound HSA. In which case, binding of one (or all) of the available sites, either individually or in concert, may be necessary to affect HSA stability as detected by a shift in $T_{m}$. For example, naproxen has up to 10 binding sites on the HSA structure with binding constant values within an order of magnitude of one another. ${ }^{9}$ This was consistent with our observed stoichiometry for naproxen of $n=10.8$. Note, that these binding effects need not be exclusive and could occur simultaneously.

Thus, for single ligand binding at a single site, $K_{D}$ values obtained using either $T_{m}$ or $\Delta G_{c a l}\left(37^{\circ} \mathrm{C}\right)$ would be expected to be essentially the same (as observed). However, for binding multiple ligands at a single site prior to saturation, measured $T_{m}$ may be largely unaffected until several binding events have taken place at the site and saturation binding is approached. The result was observation of a shifted D-R curve for $T_{m}$ (by a factor of $\mathrm{n}$, the binding stoichiometry) compared to those for $\Delta G_{c a l}\left(37^{\circ} \mathrm{C}\right)$. This resulted in differing values for the binding constants obtained from the analysis of $T_{m}$ or $\Delta G_{c a l}\left(37^{\circ} \mathrm{C}\right)$ D-R curves as a function of ligand concentration. In effect, there were actually two binding constants, i.e. $K_{D\left(T_{m}\right)}$ and $K_{D\left(\Delta G_{c a l}\left(37^{\circ} \mathrm{C}\right)\right)}$ evaluated. The ratio $K_{D\left(T_{m}\right)} / K_{D\left(\Delta G_{\text {cal }}\left(37^{\circ} \mathrm{C}\right)\right)}$ provided semi-quantitative estimates of the binding stoichiometry, $\mathrm{n}$. As shown in Table 1 the very good agreement between estimated $n$ values with those reported in the literature for the same ligands supports validity of the above proposition. $K_{D}$ values derived from $\Delta G_{c a l}\left(37^{\circ} \mathrm{C}\right)$ comprised the ensemble of thermodynamic contributions of ligand binding to HSA. Individual evaluated thermodynamic parameters for binding obtained from thermograms can also yield additional insight and provide a means for further classification of drug interactions with HSA.

Binding Thermodynamics: Formation of drug/protein complexes requires several specific events. These include: disruption of non-covalent interactions with water for both the drug and target molecule i.e. de-solvation; conformational changes in the target and drug and formation of noncovalent interactions between them required for complexation; exchange, association, or dissociation of ions, protons and small molecules that also accompany drug binding. Each of these events can contribute to binding affinity in different ways, but all manifest in values of binding contributions to the enthalpy $\Delta H_{B}$ and entropy, $\Delta S_{B}$. In our analysis $\Delta H_{B}=\Delta H_{H S A \cdot L}-$ 
$\Delta H_{H S A} . \Delta H_{H S A}$ is the melting enthalpy of HSA alone and $\Delta H_{H S A \cdot L}=\Delta H_{c a l}$ is the denaturation enthalpy measured for the HSA-ligand complexes. $\Delta G_{c a l}\left(37^{\circ} \mathrm{C}\right)$ for the ligand-bound complexes and HSA alone were derived from values of $\Delta H_{c a l}, \Delta S_{\text {cal }}$ and $T_{m}$. Then $\Delta G_{B}\left(37^{\circ} C\right)=$ $\Delta G_{H S A \cdot L}\left(37^{\circ} \mathrm{C}\right)-\Delta G_{H S A}\left(37^{\circ} \mathrm{C}\right)$. It should be noted that $\Delta G_{B}\left(37^{\circ} \mathrm{C}\right)$ does not necessarily equal $\Delta G_{B}^{\prime}=-R(310 K) \ln K_{D} . \Delta G_{B}\left(37^{\circ} \mathrm{C}\right)$ contains energetic contributions to binding mentioned above that effect thermal denaturation of the ligand-bound protein. Therefore $\Delta G^{\prime}{ }_{B}\left(37^{\circ} \mathrm{C}\right)$ calculated from D-R curves was considered to be the energy only due to ligand binding, not including other thermodynamic effects that might also contribute to the measured $\Delta G_{B}\left(37^{\circ} \mathrm{C}\right)$. To denote $T_{m}$ changes caused by ligand binding $\Delta T_{m}$ is used where $\Delta T_{m}=T_{m}(H S A \cdot L)-$ $T_{m}(H S A)$.

\begin{tabular}{|c|c|c|c|}
\hline Drug & $\Delta \mathrm{H}_{\mathrm{B}}\left(\mathrm{kcal} \mathrm{mol} \mathrm{k}^{-1}\right)$ & $\Delta G_{0}\left(\mathrm{kcal} \mathrm{mol}^{-1}\right)$ & $\Delta T_{m}\left({ }^{\circ} \mathrm{Cl}\right.$ \\
\hline \multicolumn{4}{|c|}{ Test Compounds } \\
\hline bromocresol green & 23.21 & 3.82 & 6.29 \\
\hline naproxen & 44.67 & 5.68 & 5.52 \\
\hline chloroquine & 64.36 & 5.25 & 1.43 \\
\hline Multihance & 49.36 & 4.37 & 1.75 \\
\hline Ablavar & 51.71 & 6.85 & 6.53 \\
\hline tetracaine & 41.68 & 4.37 & 3.16 \\
\hline captopril & 57.44 & 4.56 & -0.41 \\
\hline caffeine & 94.13 & 8.00 & 0.47 \\
\hline thimerosal & 73.93 & 14.30 & 16.67 \\
\hline fluorescein & 62.97 & 8.89 & 7.95 \\
\hline metformin & 52.57 & 4.27 & -0.31 \\
\hline metoprolol & 50.60 & 4.06 & -0.40 \\
\hline buproprion & 44.25 & 3.99 & 0.62 \\
\hline \multicolumn{4}{|c|}{ Unknown Compounds } \\
\hline DM1157 & 60.24 & 4.70 & 0.60 \\
\hline BP-DOTA (side) & 25.18 & 4.05 & 6.10 \\
\hline BP-DOTA (corner) & 50.76 & 7.37 & 7.80 \\
\hline NBAM-DO3A & 35.54 & 3.92 & 4.87 \\
\hline BPAM-DO3A & 71.99 & 7.74 & 4.55 \\
\hline \multicolumn{4}{|c|}{ Insoluble or Poorly Soluble } \\
\hline digitoxin & 32.62 & 4.74 & 3.92 \\
\hline ibuprofen & 119.54 & 23.59 & 19.53 \\
\hline decanoic acid & 147.52 & 30.28 & 24.56 \\
\hline$\Delta 9$-tetrahydrocannabinol & 51.40 & 4.45 & 0.28 \\
\hline$\beta$-Estradiol & 47.60 & 4.53 & 0.92 \\
\hline bilirubin & 47.27 & 4.15 & 0.30 \\
\hline Error & $\pm 7 \%$ & \pm 0.15 & \pm 0.15 \\
\hline
\end{tabular}


Thus, a direct link exists between structural stability of HSA and melting stability of ligand-bound HSA complexes. Our approach involves exploiting this linkage by evaluating binding constants through measurements of the effects of ligand binding on the thermodynamics of ligand-bound protein denaturation. An added benefit of our DSC-based analytical process is the enhanced insight that can be gained into relationships between specific physical (stereochemical) and chemical (functional group) features and their effects on protein binding. In particular, as shown below, dissecting the effects on binding activity of different derivatives with specific modifications of a central compound can prove to be most insightful.

Examination of thermodynamic binding parameters listed in Table 2 provides three examples highlighting how semi-quantitative thermodynamic measurements can inform on specific features that might be considered in drug design choices. These are: (1) BP-DOTA (side) and (corner), (2) NBAM-DO3A and BPAM-DO3A, and (3) chloroquine and DM1157. Selected compounds contain examples of stereoisomers and two functional isomers.

First, consider several novel analogs of commercially available gadolinium-based contrast agents used for in vivo NMR imaging (generous gifts of Professor Mark Woods and Dr. Lauren Rust). DSC measurements of these compounds provided a quantitative metric by which to gauge effects of different specific chemical modifications of the drugs on HSA binding. Specifically, Dotarem (DOTA) and Prohance (DO3A) have been reported to not bind measurably to HSA. ${ }^{42}$ Our analysis concurred and thermograms of drug/HSA mixtures were identical to HSA alone with no binding detected. In contrast, functional and stereochemical modifications of these compounds conferred appreciable HSA binding activity; seen through unique responses of the measured thermograms of their mixtures with HSA, and corresponding evaluated thermodynamic parameters as described below.

Modified forms, BP-DOTA (side) and (corner) are novel stereoisomers of Dotarem ${ }^{83}$ (generous gift of Professor Mark Woods and Dr. Lauren Rust, Portland State University). For these compounds, the DOTA structure was modified with a biphenyl thiourea functional group. ${ }^{83}$ The primary difference between the side and corner isomers of BP-DOTA is the different regiochemistry of the $\mathrm{BP}$ functional substituents on the chelate structure. ${ }^{83}$ Binding data in Table 1 for the BP-DOTA compounds indicated little difference in the average binding constants $K_{D}$ of 8.6 $\mu \mathrm{M}$ and $11.4 \mu \mathrm{M}$, for the side and corner isomers, respectively. However, measured thermodynamic binding parameters were significantly different.

Even though BP-DOTA (side) and BP-DOTA (corner) displayed very similar binding constants for $\mathrm{HSA}$, the enthalpic contributions to binding, $\Delta H_{B}$, were significantly different at $25.18 \mathrm{kcal} / \mathrm{mol}$ for BP-DOTA (side) and $50.76 \mathrm{kcal} / \mathrm{mol}$ for BP-DOTA (corner). Likewise, BP-DOTA (corner) displayed greater $\Delta G_{B}$ and $\Delta T_{m}$ than BP-DOTA (side). These significant differences suggested a potentially important role of stereochemical structure on HSA binding of drugs within this compound family. These results highlighted how apparently identical compounds with similar binding constants could display significantly different thermodynamic contributions of drug binding to HSA thermostability. It would be much more difficult to obtain comparable results 
using other methods (NMR, ITC and SPR) commonly applied to assay ligand/protein binding. Our method provided unique information, i.e. both compounds displayed essentially the same binding constants, but very different thermodynamic contributions of binding to HSA thermostability.

Second, consider NBAM-DO3A and BPAM-DO3A, novel functional isomers of Prohance (unpublished, generous gift of Professor Mark Woods and Dr. Lauren Rust, Portland State University). NBAM-DO3A contains a nitrobenzyl group and BPAM-DO3A contains a biphenyl located at the same position on the chelate (DO3A). In contrast to the BP-DOTA compounds above, these DO3A derivatives displayed significantly different average binding constants. With $K_{D}=70.2 \mu \mathrm{M}$ and $16.58 \mu \mathrm{M}$ for NBAM and BPAM, respectively. Notably, for the weaker binder NBAM, $\Delta H_{B}=35.54 \mathrm{kcal} / \mathrm{mol}$, half the $\Delta H_{B}$ of BPAM at $71.99 \mathrm{kcal} / \mathrm{mol}$. Similarly, $\Delta G_{B}$ for NBAM $(3.92 \mathrm{kcal} / \mathrm{mol})$ was approximately $50 \%$ of that for BPAM $(7.74 \mathrm{kcal} / \mathrm{mol})$. Both compounds had similar $\Delta T_{m}$ values. Evaluated stoichiometries were $n=2$ for BPAM and $n=1$ for NBAM. After accounting for differences in estimated stoichiometry for BPAM-DO3A and BP-DOTA, the compounds displayed remarkably similar binding constants. This despite differences in the DOTA and DO3A chelates. Thus, the functional biphenyl modification conferred $\sim 11 \mu \mathrm{M}$ binding to the chelates that otherwise did not bind HSA. In this case the functional derivates (NBAM and BPAM) showed differences in both HSA binding and thermodynamic stability.

Third, consider chloroquine, an antimalarial drug, and DM1157 a novel reversed chloroquine compound consisting of a chloroquine backbone with an attached reversal agent (Generous gift from Professor David Peyton and Dr. Katherine Liebman, Portland State University). ${ }^{25-27}$ Unlike the DOTA and DO3A examples above, chloroquine and DM1157 displayed essentially identical thermodynamic contributions of binding to HSA thermodynamic stability, i.e. $\Delta H_{B}=\sim 60$ $\mathrm{kcal} / \mathrm{mol}, \Delta G_{B}=\sim 5 \mathrm{kcal} / \mathrm{mol}$, and $\Delta T_{m}=\sim 1^{\circ} \mathrm{C}$ for both compounds. It might be expected given the similar thermodynamic behaviors of the compounds they would display similar binding constants. However, this was not the case. For Chloroquine $K_{D}=33.97 \mu \mathrm{M}$ while $K_{D}=0.91 \mu \mathrm{M}$ for DM1157. The binding constants differ by almost two orders of magnitude! These results indicated that attachment of the reversal agent conferred a much stronger binding constant compared to the unmodified chloroquine. Even though binding of the bulky reversal agent did not significantly affect thermostability of bound HSA. This was consistent with the general observation for these compounds as ligand size did not necessary correlate with thermodynamic stability.

Of 28 drug compounds examined 22 were reported to be soluble in water. Six were reportedly insoluble. Generally, between 40 and $70 \%$ of new chemical entities entering the drug development pipeline potentially face bioavailability issues due to low aqueous solubility. ${ }^{84}$ Difficulties and limitations imposed by poor solubility can compromise binding reactions in aqueous environments where most binding experiments were conducted. As an alternative, binding measurements can be performed in organic solvents but could have potentially deleterious effects on the structure and stability of the protein substrate. The organic environment could also adversely affect the stability of ligand/substrate complexes. ${ }^{85}$ To avoid 
potential problems associated with poor solubility, a novel sample preparation methodology was invoked. Minimum amounts of drug sample (milligrams) are required with complete avoidance of organic solvents in drug/HSA solutions. The method leverages one of the truly remarkable intrinsic properties of HSA. That is the ability of the protein to accommodate extraordinary levels of ligand binding and actually increase ligand solubility in plasma up to seven times higher than the normal solubility limit. ${ }^{86}$ This ubiquitous binding proclivity of HSA forms the basis for the HSAassisted sample preparation method that was used. It enabled the solubility of normally insoluble compounds in aqueous mixtures with HSA. Effectiveness of the HSA-mediated solubility process was clearly demonstrated for six poorly aqueous soluble compounds denoted by an asterisk in Fig 1 and Table 1. Evaluated binding constants for these compounds with HSA were in excellent agreement with literature reports. Application of this process expands capabilities of DSC for screening potential drug/ligand candidates.

\section{Conclusion}

A number of techniques have been applied to evaluate protein/ligand binding constants and assess drug-HSA binding. These include equilibrium dialysis, ultrafiltration, absorbance and fluorescence spectroscopy, isothermal titration calorimetry (ITC) and Surface Plasmon Resonance (SPR). Of these, ITC and SPR are most comparable (label-free) with our method.

ITC can provide precise evaluation of binding thermodynamics and binding constants at specific temperatures. Despite the sensitivity of ITC, the experiment is not easily scalable for applications in preclinical drug discovery. ITC requires a skilled practitioner to perform experiments, and large sample volumes at high concentrations. In the standard format ITC is incapable of highthroughput applications. Despite being able to deliver perhaps the most quantitatively accurate binding information, because of the inherent drawbacks, ITC has been sparingly employed for drug screening. ${ }^{11}$ Alternatively, the use of SPR for drug binding assays has become a popular screening technique in the drug development industry.

SPR is a label-free detection scheme purported to provide important information about binding of ligands and small molecules to plasma proteins. In fact, SPR has become a method of some choice to examine equilibrium and kinetics of ligand/drug binding. Although potentially quite informative, SPR has short comings and is not without attendant difficulties. SPR does not provide complete information. For example, SPR cannot supply any insight into binding stoichiometry. Another major deficiency of SPR is that proteins or ligands must be immobilized to a surface. For HSA binding, the protein is affixed using a sulfo-NHS reagent. ${ }^{87,} 88$ As recently reported this reagent was used to modify HSA with NHS-biotin. ${ }^{15}$ Modification of HSA molecules acted to decrease measured ligand binding constants by factors from three to $100 .{ }^{15}$ Although SPR is able to quite accurately detect the presence of ligand binding to surface-bound HSA, effects of modifications of HSA (required for surface attachment) on ligand binding can be difficult to gauge. Thus, it can be difficult to evaluate quantitatively accurate binding constants, for natural proteins, from SPR measurements alone. A comparable label-free alternative that uses natural HSA could provide more quantitatively accurate assessment of ligand binding. Ours is such a method.

In this study we employed our recently reported DSC-based process to evaluate HSA binding parameters for 28 different drugs. ${ }^{15}$ Four of the compounds did not display any detectable 
binding activity; and six were insoluble in aqueous solutions. Results demonstrated quantitatively accurate evaluations of drug-HSA binding constants and semi-quantitative estimates of binding stoichiometries. For all compounds examined, regardless of aqueous solubility, the near universal agreement with published data for known drug/HSA binding constants attests to the general accuracy and robustness of the approach. Results demonstrated a number of many attractive advantages of our method over more laborious and labor intensive, less accurate, slower and less informative ligand screening techniques such as ITC and SPR. Advantages of the method have the potential to considerably improve the pre-clinical drug screening process. More effective preclinical screening can reduce drug development costs, and lead to production of more successful drugs with lower prices; a major goal of modern healthcare management.

\section{Acknowledgements}

We thank Professors David Peyton, Rob Strongin, Mark Woods and Dr. Laura Rust, (Chemistry Department, Portland State University) for their generous gifts of drug compounds and helpful advice.

\section{References:}

1. Anderson, L.; Anderson, N. G., High resolution two-dimensional electrophoresis of human plasma proteins. Proc Natl Acad Sci U S A 1977, 74 (12), 5421-5.

2. Anderson, N. L.; Anderson, N. G., The human plasma proteome: history, character, and diagnostic prospects. Mol Cell Proteomics 2002, 1 (11), 845-67.

3. Anderson, N. L.; Polanski, M.; Pieper, R.; Gatlin, T.; Tirumalai, R. S.; Conrads, T. P.; Veenstra, T. D.; Adkins, J. N.; Pounds, J. G.; Fagan, R.; Lobley, A., The human plasma proteome: a nonredundant list developed by combination of four separate sources. Mol Cell Proteomics 2004, 3 (4), 311-26.

4. Omenn, G. S.; States, D. J.; Adamski, M.; Blackwell, T. W.; Menon, R.; Hermjakob, H.; Apweiler, R.; Haab, B. B.; Simpson, R. J.; Eddes, J. S.; Kapp, E. A.; Moritz, R. L.; Chan, D. W.; Rai, A. J.; Admon, A.; Aebersold, R.; Eng, J.; Hancock, W. S.; Hefta, S. A.; Meyer, H.; Paik, Y. K.; Yoo, J. S.; Ping, P.; Pounds, J.; Adkins, J.; Qian, X.; Wang, R.; Wasinger, V.; Wu, C. Y.; Zhao, X.; Zeng, R.; Archakov, A.; Tsugita, A.; Beer, I.; Pandey, A.; Pisano, M.; Andrews, P.; Tammen, H.; Speicher, D. W.; Hanash, S. M., Overview of the HUPO Plasma Proteome Project: results from the pilot phase with 35 collaborating laboratories and multiple analytical groups, generating a core dataset of 3020 proteins and a publicly-available database. Proteomics 2005, 5 (13), 3226-45.

5. Peters Jr, T., All about albumin: biochemistry, genetics, and medical applications. Academic press: 1995.

6. Sudlow, G.; Birkett, D.; Wade, D., Further characterization of specific drug binding sites on human serum albumin. Molecular pharmacology 1976, 12 (6), 1052-1061.

7. Fasano, M.; Curry, S.; Terreno, E.; Galliano, M.; Fanali, G.; Narciso, P.; Notari, S.; Ascenzi, P., The extraordinary ligand binding properties of human serum albumin. IUBMB life 2005, 57 (12), 787-796.

8. Eaton, Joshua D.; Williamson, Mike P., Multi-site binding of epigallocatechin gallate to human serum albumin measured by NMR and isothermal titration calorimetry. Bioscience Reports 2017, 37 (3), BSR20170209. 
9. Lejon, S.; Cramer, J. F.; Nordberg, P., Structural basis for the binding of naproxen to human serum albumin in the presence of fatty acids and the GA module. Acta Crystallogr Sect F Struct Biol Cryst Commun 2008, 64 (Pt 2), 64-9.

10. Tang, J.; Luan, F.; Chen, X., Binding analysis of glycyrrhetinic acid to human serum albumin: fluorescence spectroscopy, FTIR, and molecular modeling. Bioorganic \& medicinal chemistry 2006, 14 (9), 3210-3217.

11. Ronzetti, M.; Baljinnyam, B.; Yasgar, A.; Simeonov, A., Testing for drug-human serum albumin binding using fluorescent probes and other methods. Expert opinion on drug discovery 2018, 13 (11), 1005-1014.

12. Fish, D. J.; Brewood, G. P.; Kim, J. S.; Garbett, N. C.; Chaires, J. B.; Benight, A. S., Statistical analysis of plasma thermograms measured by differential scanning calorimetry. Biophysical Chemistry 2010, 152 (1), 184-190.

13. Wisniewski, M.; Garbett, N.; Fish, D.; Brewood, G.; Miller, J.; Chaires, J.; Benight, A., Differential scanning calorimetry in molecular diagnostics. Vitro Diagnostic Technology 2011, 17, 29-34.

14. Rai, S. N.; Pan, J.; Cambon, A.; Chaires, J.; Garbett, N., Group classification based on highdimensional data: application to differential scanning calorimetry plasma thermogram analysis of cervical cancer and control samples. Open Access Medical Statistics 2013, 3, 1-9.

15. Eskew, M. W.; Koslen, M. M.; Benight, A. S., Ligand binding to natural and modified human serum albumin. Analytical Biochemistry 2021, 612 (1), 113843.

16. Celej, M. S.; Dassie, S. A.; Freire, E.; Bianconi, M. L.; Fidelio, G. D., Ligand-induced thermostability in proteins: Thermodynamic analysis of ANS-albumin interaction. Biochimica et Biophysica Acta (BBA)Proteins and Proteomics 2005, 1750 (2), 122-133.

17. Dassie, S. A.; Celej, M. S.; Fidelio, G. D., Protein unfolding coupled to ligand binding: differential scanning calorimetry simulation approach. Journal of chemical education 2005, 82 (1), 85.

18. Shrake, A.; Frazier, D.; Schwarz, F. P., Thermal stabilization of human albumin by medium-and short-chain n-alkyl fatty acid anions. Biopolymers: Original Research on Biomolecules 2006, 81 (4), 235248.

19. Shrake, A.; Ross, P. D., Ligand-induced biphasic protein denaturation. Journal of Biological Chemistry 1990, 265 (9), 5055-5059.

20. Shrake, A.; Finlayson, J.; Ross, P., Thermal Stability of Human Albumin Measured by Differential Scanning Calorimetry: I. Effects of Caprylate and N-Acetyltryptophanate. Vox sanguinis 1984, 47 (1), 718.

21. Al-Hazmi, A. A.; Waddhaah, M.; Al-asbahy, F. A.; Esmail, S. A. A.; Shamsi, M.; Al-Sabahi, S. M.; Labeeb, M. S., Synthesis and Characterization of Some Carbohydrizide Derivatives: Interaction Studies with Human Serum Albumin (HSA), Molecular Docking and Photo-Induced Cleavage. AASCIT Journal of Chemistry 2019, 5 (1), 1-13.

22. Fu, X.-B.; Lin, Z.-H.; Liu, H.-F.; Le, X.-Y., A new ternary copper (II) complex derived from 2-(2'pyridyl) benzimidazole and glycylglycine: synthesis, characterization, DNA binding and cleavage, antioxidation and HSA interaction. Spectrochimica Acta Part A: Molecular and Biomolecular Spectroscopy 2014, 122, 22-33.

23. David, S.; Balaram, P.; Mathan, V., Characterization of the interaction of lipid A and lipopolysaccharide with human serum albumin: implications for an endotoxin carrier function for albumin. Journal of Endotoxin Research 1995, 2 (2), 99-106.

24. Pace, C. N.; Vajdos, F.; Fee, L.; Grimsley, G.; Gray, T., How to measure and predict the molar absorption coefficient of a protein. Protein science 1995, 4 (11), 2411-2423.

25. Liebman, K. M.; Burgess, S. J.; Gunsaru, B.; Kelly, J. X.; Li, Y.; Morrill, W.; Liebman, M. C.; Peyton, D. H., Unsymmetrical Bisquinolines with High Potency against P. falciparum Malaria. Molecules 2020, 25 (9), 2251. 
26. Peyton, D., Latter-stage preclinical developmental work on PL69/DM1157. Malaria Journal 2014, 13 (S1), P70.

27. Burgess, S. J.; Kelly, J. X.; Shomloo, S.; Wittlin, S.; Brun, R.; Liebmann, K.; Peyton, D. H., Synthesis, structure- activity relationship, and mode-of-action studies of antimalarial reversed chloroquine compounds. Journal of medicinal chemistry 2010, 53 (17), 6477-6489.

28. Hoang, H.; Manyanga, F.; Morakinyo, M. K.; Pinkert, V.; Sarwary, F.; Fish, D. J.; Brewood, G. P.; Benight, A. S., Effects of Selective Biotinylation on the Thermodynamic Stability of Human Serum Albumin. Journal of Biophysical Chemistry 2016, 7 (01), 9.

29. Koslen, M. M.; Eskew, M. W.; Pinkert, V.; Hoang, H.; Manyanga, F.; Dean, W. L.; Chaires, J. B.; Benight, A. S., Capture Reagent and Strategy for Retrieving Albumin-Bound Ligands from Plasma. Advances in Biological Chemistry 2019, 9 (3).

30. Gesztelyi, R.; Zsuga, J.; Kemeny-Beke, A.; Varga, B.; Juhasz, B.; Tosaki, A., The Hill equation and the origin of quantitative pharmacology. Archive for history of exact sciences 2012, 66 (4), 427-438.

31. Meddings, J.; Scott, R.; Fick, G., Analysis and comparison of sigmoidal curves: application to dose-response data. American Journal of Physiology-Gastrointestinal and Liver Physiology 1989, 257 (6), G982-G989.

32. Tallarida, R. J.; Jacob, L. S., The Dose-Response Relation in Pharmacology. Springer Science \& Business Media: 2012.

33. Lee Rodkey, F., Binding of bromocresol green by human serum albumin. Archives of Biochemistry and Biophysics 1964, 108 (3), 510-513.

34. Honoré, B.; Brodersen, R., Albumin binding of anti-inflammatory drugs. Utility of a site-oriented versus a stoichiometric analysis. Molecular pharmacology 1984, 25 (1), 137-150.

35. Mortensen, A.; Jensen, E. B.; Petersen, P. B.; Husted, S.; Andreasen, F., The determination of naproxen by spectrofluorometry and its binding to serum proteins. Acta pharmacologica et toxicologica 1979, 44 (4), 277-283.

36. Lammers, I.; Lhiaubet-Vallet, V.; Ariese, F.; Miranda, M. A.; Gooijer, C., Binding of naproxen enantiomers to human serum albumin studied by fluorescence and room-temperature phosphorescence. Spectrochimica Acta Part A: Molecular and Biomolecular Spectroscopy 2013, 105, 6773.

37. Cheruvallath, V.; Riley, C.; Narayanan, S.; Lindenbaum, S.; Perrin, J., A quantitative circular dichroic investigation of the binding of the enantiomers of ibuprofen and naproxen to human serum albumin. Journal of pharmaceutical and biomedical analysis 1997, 15 (11), 1719-1724.

38. Tunç, S.; Duman, O.; Bozoğlan, B. K., Studies on the interactions of chloroquine diphosphate and phenelzine sulfate drugs with human serum albumin and human hemoglobin proteins by spectroscopic techniques. Journal of Luminescence 2013, 140, 87-94.

39. Ofori-Adjei, D.; Ericsson, O.; Lindstrom, B.; Sjoqvist, F., Protein binding of chloroquine enantiomers and desethylchloroquine. British journal of clinical pharmacology 1986, 22 (3), 356-358.

40. Huang, Y.; Pan, W.; Guo, M.; Yao, S., Capillary electrophoresis with end-column electrochemiluminescence for the analysis of chloroquine phosphate and the study on its interaction with human serum albumin. Journal of Chromatography A 2007, 1154 (1-2), 373-378.

41. Henrotte, V.; Vander Elst, L.; Laurent, S.; Muller, R. N., Comprehensive investigation of the noncovalent binding of MRI contrast agents with human serum albumin. JBIC Journal of Biological Inorganic Chemistry 2007, 12 (6), 929-937.

42. Laurent, S.; Elst, L. V.; Muller, R. N., Comparative study of the physicochemical properties of six clinical low molecular weight gadolinium contrast agents. Contrast media \& molecular imaging 2006, 1 (3), 128-137.

43. Caravan, P.; Cloutier, N. J.; Greenfield, M. T.; McDermid, S. A.; Dunham, S. U.; Bulte, J. W. M.; Amedio, J. C.; Looby, R. J.; Supkowski, R. M.; Horrocks, W. D.; McMurry, T. J.; Lauffer, R. B., The 
Interaction of MS-325 with Human Serum Albumin and Its Effect on Proton Relaxation Rates. Journal of the American Chemical Society 2002, 124 (12), 3152-3162.

44. Muller, R. N.; Radüchel, B.; Laurent, S.; Platzek, J.; Piérart, C.; Mareski, P.; Vander Elst, L., Physicochemical characterization of MS-325, a new gadolinium complex, by multinuclear relaxometry. European journal of inorganic chemistry 1999, 1999 (11), 1949-1955.

45. Chilom, C., Nistorescu, A, A spectroscopic study of the interaction of HSA with tetracaine. Indian Journal of Biochemistry and Biophysics 2016, 53, 206-211.

46. Kaur, A.; Banipal, P. K.; Banipal, T. S., Local anesthetic-bovine serum albumin interactional behaviour: Characterization by volumetric, calorimetric, and spectroscopic methods. Journal of Molecular Liquids 2017, 243, 91-101.

47. Gao, X.; Tang, Y.; Rong, W.; Zhang, X.; Zhao, W.; Zi, Y., Analysis of binding interaction between captopril and human serum albumin. American Journal of Analytical Chemistry 2011, 2 (02), 250.

48. Liu, T.-T.; Xiang, L.-L.; Wang, J.-L.; Chen, D.-Y., Application of capillary electrophoresis-frontal analysis for comparative evaluation of the binding interaction of captopril with human serum albumin in the absence and presence of hydrochlorothiazide. Journal of pharmaceutical and biomedical analysis 2015, 115, 31-35.

49. Wu, Q.; Li, C.; Hu, Y.; Liu, Y., Study of caffeine binding to human serum albumin using optical spectroscopic methods. Science in China Series B: Chemistry 2009, 52 (12), 2205.

50. Islam, M. M.; Sonu, V. K.; Gashnga, P. M.; Moyon, N. S.; Mitra, S., Caffeine and sulfadiazine interact differently with human serum albumin: A combined fluorescence and molecular docking study. Spectrochimica Acta Part A: Molecular and Biomolecular Spectroscopy 2016, 152, 23-33.

51. Kriško, A.; llakovac Kveder, M.; Pečar, S.; Pifat, G., A study of caffeine binding to human serum albumin. 2005.

52. Zhang, H.-M.; Chen, T.-T.; Zhou, Q.-H.; Wang, Y.-Q., Binding of caffeine, theophylline, and theobromine with human serum albumin: A spectroscopic study. Journal of molecular structure 2009, 938 (1-3), 221-228.

53. Santos, J. C. N.; da Silva, I. M.; Braga, T. C.; de Fátima, Â.; Figueiredo, I. M.; Santos, J. C. C., Thimerosal changes protein conformation and increase the rate of fibrillation in physiological conditions: Spectroscopic studies using bovine serum albumin (BSA). International journal of biological macromolecules 2018, 113, 1032-1040.

54. Abou-Zied, O. K.; Sulaiman, S. A., Site-specific recognition of fluorescein by human serum albumin: A steady-state and time-resolved spectroscopic study. Dyes and Pigments 2014, 110, 89-96.

55. Penniston, J. T., Fluorescence polarization measurement of binding of fluorescein to albumin. Experimental eye research 1982, 34 (3), 435-443.

56. Rahnama, E.; Mahmoodian-Moghaddam, M.; Khorsand-Ahmadi, S.; Saberi, M. R.; Chamani, J., Binding site identification of metformin to human serum albumin and glycated human serum albumin by spectroscopic and molecular modeling techniques: a comparison study. Journal of Biomolecular Structure and Dynamics 2015, 33 (3), 513-533.

57. Sharma, D.; Ojha, H.; Pathak, M.; Singh, B.; Sharma, N.; Singh, A.; Kakkar, R.; Sharma, R. K., Spectroscopic and molecular modelling studies of binding mechanism of metformin with bovine serum albumin. Journal of Molecular Structure 2016, 1118, 267-274.

58. Duman, O.; Tunç, S.; Bozoğlan, B. K., Characterization of the binding of metoprolol tartrate and guaifenesin drugs to human serum albumin and human hemoglobin proteins by fluorescence and circular dichroism spectroscopy. Journal of fluorescence 2013, 23 (4), 659-669.

59. Rahman, M.; Prianka, F.; Shohel, M.; Mazid, M. A., Interaction of palmitic acid with metoprolol succinate at the binding sites of bovine serum albumin. Advanced pharmaceutical bulletin 2014, 4 (4), 379. 
60. Manjushree, M.; Revanasiddappa, H., Interpretation of the binding interaction between bupropion hydrochloride with human serum albumin: A collective spectroscopic and computational approach. Spectrochimica Acta Part A: Molecular and Biomolecular Spectroscopy 2019, 209, 264-273. 61. Bujard, A.; Petit, C.; Carrupt, P.-A.; Rudaz, S.; Schappler, J., HDM-PAMPA to predict gastrointestinal absorption, binding percentage, equilibrium and kinetics constants with human serum albumin and using 2 end-point measurements. European Journal of Pharmaceutical Sciences 2017, 97, 143-150.

62. Kragh-Hansen, U., Relations between high-affinity binding sites of markers for binding regions on human serum albumin. Biochemical Journal 1985, 225 (3), 629-638.

63. Hage, D. S.; Sengupta, A., Characterisation of the binding of digitoxin and acetyldigitoxin to human serum albumin by high-performance affinity chromatography. Journal of Chromatography $B$ : Biomedical Sciences and Applications 1999, 724 (1), 91-100.

64. Day, Y. S.; Myszka, D. G., Characterizing a drug's primary binding site on albumin. Journal of pharmaceutical sciences 2003, 92 (2), 333-343.

65. Kragh-Hansen, U., Molecular aspects of ligand binding to serum albumin. Pharmacological reviews 1981, 33 (1), 17.

66. Itoh, T.; Saura, Y.; Tsuda, Y.; Yamada, H., Stereoselectivity and enantiomer-enantiomer interactions in the binding of ibuprofen to human serum albumin. Chirality 1997, 9 (7), 643-649.

67. Ashbrook, J. D.; Spector, A. A.; Santos, E. C.; Fletcher, J., Long chain fatty acid binding to human plasma albumin. Journal of Biological Chemistry 1975, 250 (6), 2333-2338.

68. Ashbrook, J. D.; Spector, A. A.; Fletcher, J. E., Medium chain fatty acid binding to human plasma albumin. Journal of Biological Chemistry 1972, 247 (21), 7038-7042.

69. Koh, S.-W. M.; Means, G. E., Characterization of a small apolar anion binding site of human serum albumin. Archives of biochemistry and biophysics 1979, 192 (1), 73-79.

70. Fanali, G.; Cao, Y.; Ascenzi, P.; Trezza, V.; Rubino, T.; Parolaro, D.; Fasano, M., Binding of $89-$ tetrahydrocannabinol and diazepam to human serum albumin. IUBMB life 2011, 63 (6), 446-451.

71. Danesh, N.; Navaee Sedighi, Z.; Beigoli, S.; Sharifi-Rad, A.; Saberi, M. R.; Chamani, J., Determining the binding site and binding affinity of estradiol to human serum albumin and holo-transferrin: fluorescence spectroscopic, isothermal titration calorimetry and molecular modeling approaches. Journal of Biomolecular Structure and Dynamics 2018, 36 (7), 1747-1763.

72. Heringa, M. B.; Pastor, D.; Algra, J.; Vaes, W. H.; Hermens, J. L., Negligible depletion solid-phase microextraction with radiolabeled analytes to study free concentrations and protein binding: an example with [3H] estradiol. Analytical chemistry 2002, 74 (23), 5993-5997.

73. MOLL JR, G. W.; ROSENFIEL JR, R. L.; HELKE, J. H., Estradiol-testosterone binding interactions and free plasma estradiol under physiological conditions. The Journal of Clinical Endocrinology \& Metabolism 1981, 52 (5), 868-874.

74. Moradi, N.; Ashrafi-Kooshk, M. R.; Chamani, J.; Shackebaei, D.; Norouzi, F., Separate and simultaneous binding of tamoxifen and estradiol to human serum albumin: Spectroscopic and molecular modeling investigations. Journal of Molecular Liquids 2018, 249, 1083-1096.

75. Jacobsen, J., Binding of bilirubin to human serum albumin-determination of the dissociation constants. FEBS letters 1969, 5 (2), 112-114.

76. Petersen, C. E.; Ha, C.-E.; Harohalli, K.; Feix, J. B.; Bhagavan, N. V., A dynamic model for bilirubin binding to human serum albumin. Journal of Biological Chemistry 2000, 275 (28), 20985-20995.

77. Berde, C. B.; Hudson, B. S.; Simoni, R. D.; Sklar, L., Human serum albumin. Spectroscopic studies of binding and proximity relationships for fatty acids and bilirubin. Journal of Biological Chemistry 1979, 254 (2), 391-400. 
78. Bal, W.; Sokołowska, M.; Kurowska, E.; Faller, P., Binding of transition metal ions to albumin: sites, affinities and rates. Biochimica et Biophysica Acta (BBA)-General Subjects 2013, 1830 (12), 54445455.

79. Li, Y.; Yan, X.-P.; Chen, C.; Xia, Y.-L.; Jiang, Y., Human Serum Albumin- Mercurial Species Interactions. Journal of proteome research 2007, 6 (6), 2277-2286.

80. O'Byrne, P. M.; Williams, R.; Walsh, J. J.; Gilmer, J. F., The aqueous stability of bupropion. Journal of pharmaceutical and biomedical analysis 2010, 53 (3), 376-381.

81. Tanwir, A.; Jahan, R.; Quadir, M. A.; Kaisar, M. A.; Hossain, M. K., Spectroscopic studies of the interaction between metformin hydrochloride and bovine serum albumin. Dhaka University Journal of Pharmaceutical Sciences 2012, 11 (1), 45-49.

82. Lin, S.-Y.; Li, M.-J.; Wei, Y.-S., Ethanol or/and captopril-induced precipitation and secondary conformational changes of human serum albumin. Spectrochimica Acta Part A: Molecular and Biomolecular Spectroscopy 2004, 60 (13), 3107-3111.

83. Rust, L.; Payne, K. M.; Carniato, F.; Botta, M.; Woods, M., Differences in the Relaxometric Properties of Regioisomeric Benzyl-DOTA Bifunctional Chelators: Implications for Molecular Imaging. Bioconjugate chemistry 2019, 30 (5), 1530-1538.

84. Thomas, F., The Demands of the Perfect Dose. Pharmaceutical Technology 2019, pp 16-20.

85. Michnik, A.; Drzazga, Z., Effect of ethanol on the thermal stability of human serum albumin. Journal of thermal analysis and calorimetry 2007, 88 (2), 449-454.

86. Baroni, S.; Mattu, M.; Vannini, A.; Cipollone, R.; Aime, S.; Ascenzi, P.; Fasano, M., Effect of ibuprofen and warfarin on the allosteric properties of haem-human serum albumin: a spectroscopic study. European journal of biochemistry 2001, 268 (23), 6214-6220.

87. Rich, R. L.; Day, Y. S.; Morton, T. A.; Myszka, D. G., High-resolution and high-throughput protocols for measuring drug/human serum albumin interactions using BIACORE. Analytical biochemistry 2001, 296 (2), 197-207.

88. Fabini, E.; Danielson, U. H., Monitoring drug-serum protein interactions for early ADME prediction through Surface Plasmon Resonance technology. Journal of pharmaceutical and biomedical analysis 2017, 144, 188-194. 